\title{
Activity of Scorpion Venom-Derived Antifungal Peptides against Planktonic Cells of Candida spp. and Cryptococcus neoformans and Candida albicans Biofilms
}

\section{OPEN ACCESS}

Edited by:

Joshua D. Nosanchuk,

Albert Einstein College of Medicine,

Reviewed by:

Rossana Cordeiro,

Universidade Federal do Ceará, Brazil

Priscila Costa Albuquerque, FIOCRUZ Oswaldo Cruz Foundation,

Brazil

*Correspondence: IIdinete Silva-Pereira ildinetesp@gmail.com;

xocolau@unb.br

†These authors share first authorship.

¥These authors share senior authorship.

Specialty section:

This article was submitted to Antimicrobials, Resistance and Chemotherapy,

a section of the journal

Frontiers in Microbiology

Received: 27 June 2016 Accepted: 02 November 2016 Published: 18 November 2016

Citation:

Guilhelmelli F, Vilela N, Smidt KS, de Oliveira MA, Álvares ACM, Rigonatto MCL, da Silva Costa PH, Tavares AH, Freitas SM, Nicola AM,

Franco OL, Derengowski LS, Schwartz EF, Mortari MR, Bocca AL,

Albuquerque $P$ and Silva-Pereira I

(2016) Activity of Scorpion

Venom-Derived Antifungal Peptides against Planktonic Cells of Candida spp. and Cryptococcus neoformans

and Candida albicans Biofilms.

Front. Microbiol. 7:1844.

doi: 10.3389/fmicb.2016.01844
Fernanda Guilhelmelli1t, Nathália Vilela ${ }^{1+}$, Karina S. Smidt' ${ }^{2}$, Marco A. de Oliveira ${ }^{1}$, Alice da Cunha Morales Álvares ${ }^{3}$, Maria C. L. Rigonatto ${ }^{2}$, Pedro H. da Silva Costa ${ }^{2}$, Aldo H. Tavares ${ }^{2}$, Sônia M. de Freitas ${ }^{3}$, André M. Nicola ${ }^{4}$, Octávio L. Franco ${ }^{5}$, Lorena da Silveira Derengowski ${ }^{1}$, Elisabeth F. Schwartz ${ }^{6}$, Márcia R. Mortari ${ }^{6}$, Anamélia L. Bocca ${ }^{2}$, Patrícia Albuquerque ${ }^{1,7 \neq}$ and Ildinete Silva-Pereira ${ }^{1 *}$

'Laboratory of Molecular Biology, Department of Cellular Biology, Institute of Biological Sciences, University of Brasilia, Brasilia, Brazil, ${ }^{2}$ Laboratory of Applied Immunology, Department of Cellular Biology, Institute of Biological Sciences, University of Brasilia, Brasilia, Brazil, ${ }^{3}$ Laboratory of Molecular Biophysics, Department of Cellular Biology, Institute of Biological Sciences, University of Brasilia, Brasilia, Brazil, ${ }^{4}$ Faculty of Medicine, University of Brasilia, Brasilia, Brazil, ${ }^{5}$ Center of Proteomic and Biochemistry Analysis, Post Graduation in Biotechnology and Genomic Sciences, Catholic University of Brasilia, Brasilia, Brazil, ${ }^{6}$ Laboratory of Neuropharmacology, Department of Physiological Sciences, Institute of Biological Sciences, University of Brasilia, Brasilia, Brazil, ${ }^{7}$ Faculty of Ceilândia, University of Brasilia, Brasilia, Brazil

The incidence of fungal infections has been increasing in the last decades, while the number of available antifungal classes remains the same. The natural and acquired resistance of some fungal species to available therapies, associated with the high toxicity of these drugs on the present scenario and makes an imperative of the search for new, more efficient and less toxic therapeutic choices. Antimicrobial peptides (AMPs) are a potential class of antimicrobial drugs consisting of evolutionarily conserved multifunctional molecules with both microbicidal and immunomodulatory properties being part of the innate immune response of diverse organisms. In this study, we evaluated 11 scorpion-venom derived non-disulfide-bridged peptides against Cryptococcus neoformans and Candida spp., which are important human pathogens. Seven of them, including two novel molecules, showed activity against both genera with minimum inhibitory concentration values ranging from 3.12 to $200 \mu \mathrm{M}$ and an analogous activity against Candida albicans biofilms. Most of the peptides presented low hemolytic and cytotoxic activity against mammalian cells. Modifications in the primary peptide sequence, as revealed by in silico and circular dichroism analyses of the most promising peptides, underscored the importance of cationicity for their antimicrobial activity as well as the amphipathicity of these molecules and their tendency to form alpha helices. This is the first report of scorpion-derived AMPs against C. neoformans and our results underline the potential of scorpion venom as a source of antimicrobials. Further characterization of their mechanism of action, followed by molecular optimization to decrease their cytotoxicity and increase antimicrobial activity, is needed to fully clarify their real potential as antifungals.

Keywords: antifungal drugs, antimicrobial peptides, Candida spp., Candida albicans, Cryptococcus neoformans, scorpions venom 


\section{INTRODUCTION}

An increase of systemic mycoses incidence due to the rising number of immunocompromised individuals, particularly cancer, HIV/AIDS and solid-organ transplant patients has been noticed in recent years. Candida spp. and Cryptococcus spp. are among the main causative agents (Romani, 2011; ArmstrongJames et al., 2014).

Candida spp. remain the most important cause of opportunistic mycoses worldwide and are associated to high mortality and morbidity rates, Candida albicans being the major agent of candidemia (Pfaller and Diekema, 2007; Mikulska et al., 2012). Furthermore, an increase in infections caused by non-albicans species has been noticed, like Candida parapsilosis, Candida tropicalis, and Candida glabrata, the latter being more resistant to antifungal drugs than other Candida species (Sobel, 2006; Pfaller and Diekema, 2007; Diekema et al., 2012; Rodrigues et al., 2014). Cryptococcus neoformans is another opportunistic pathogen of clinical relevance, especially among HIV/AIDS patients. Cryptococcal meningitis is the most important cause of death from HIV-related fungal infection worldwide (Park et al., 2009). The estimated yearly incidence of cryptococcal meningitis is almost one million cases, causing 625,000 deaths (Park et al., 2009). In addition, Candida species and $C$. neoformans can form biofilms on abiotic and biotic surfaces (Mayer et al., 2013; Martinez and Casadevall, 2015). Of particular interest is the formation of biofilms by C. albicans, which confers specialized properties to the microorganism that complicate treatment, such as the increased resistance to antimicrobial drugs and the ability to evade the host immune system, among others (Finkel and Mitchell, 2011; Fanning and Mitchell, 2012). Another problem regarding fungal infections is the rising of resistance to currently available antifungal drugs (Pan et al., 2012; Pfaller, 2012; Arendrup, 2013). This is compounded by the intrinsic resistance of some fungi to antifungals, such as C. neoformans to echinocandins and C. glabrata to azoles (Sable et al., 2008; Pfaller, 2012; Paul and Moye-Rowley, 2014).

In this scenario, there is a concrete need for new antifungals, and antimicrobial peptides (AMPs) have been promoted as promising in that regard (Hancock and Sahl, 2006), considering their low molecular masses and lower potential to induce resistance (Mookherjee and Hancock, 2007; Huang et al., 2010).

A great number of peptides are present in scorpion venom. They can be classified as disulfide-bridged peptides or nondisulfide-bridged peptides (NDBPs), the latter being the major component of their venom (Almaaytah and Albalas, 2014; Harrison et al., 2014; Ortiz et al., 2015). Most have similar physicochemical characteristics, such as a cationic character and structural flexibility. NDBPs present diverse biological activities, including antimicrobial, cytolytic, immunomodulatory, antitumor, and bradykinin-like potentiation effects (Zeng et al., 2005; Almaaytah and Albalas, 2014; Ortiz et al., 2015). In the present work, we evaluated the antifungal activity of peptides previously obtained by transcriptomic approaches from venom glands of three scorpion species (Silva et al., 2009). We classified them according to the rules proposed by Zeng et al.
(2005), who group scorpion NDBPs in six subfamilies based on their pharmacological action, length and structural similarity. The peptides presented here belong to subfamilies 3, 4, and 5 and their activity will be discussed following this classification. Some AMPs are presented here for the first time, among them five peptides from the venom of the scorpion Tityus obscurus corresponding to the first AMPs characterized in this species.

\section{MATERIALS AND METHODS}

\section{cDNAs Encoding Putative Antimicrobial Peptides}

Different cDNAs encoding putative AMPs from the venom gland of scorpions T. obscurus, Tityus costatus, Hadrurus gertschi, and Opisthacanthus cayaporum were characterized by expressed sequence tag (EST). The amino acid sequences deduced from ESTs as described in literature (Diego-Garcia et al., 2005; Schwartz et al., 2007; Silva et al., 2009; Guerrero-Vargas et al., 2012) were considered to obtain the synthetic peptides as specified bellow (Table 1).

Comparative analyses of amino acids sequences were performed employing the Basic Local Alignment Search Tool $\left(\mathrm{BLAST}^{1}\right)$ and Collection of Anti-Microbial Peptides $\left(\mathrm{CAMP}^{2}\right)$ databases to identify peptides with at least $40 \%$ of identity to our queries sequence and to which antimicrobial activity was previously determined. The multiple sequence alignments were done using the M-Coffee tool ${ }^{3}$ on the sequences identified in the previous step, and the consensus sequences were represented as a sequence logo, generated at Weblogo web server ${ }^{4}$.

\section{Chemical Peptide Synthesis}

Peptides were chemically synthesized using FMOC-Butila (AminoTech Pesquisa e Desenvolvimento LTDA, Brazil), and further purified by reverse-phase high performance liquid chromatography (HPLC). Peptides ToAP1, ToAP2S1, ToAP3, NDBP-4.23, ToAP4, and NDBP-5.7 were synthesized with C-terminal amidation. To assess the purity and sequence correctness, peptides were submitted to matrix-assisted laser desorption/ionization time of flight mass spectrometry (MALDITOF/TOF MS; UltraFlex III, Bruker Daltonics, Germany), under reflector (MS) and $\mathrm{LIFT}^{\mathrm{TM}}$ (MS/MS) positive modes. Matrix solution was prepared using $5.0 \mathrm{mg}$ of $\alpha$-cyano4-hydroxycinnamic acid (Sigma, USA) and solubilized with $250 \mu \mathrm{L}$ of acetonitrile, $200 \mu \mathrm{L}$ of deionized water, and with $50 \mu \mathrm{L}$ of an aqueous trifluoroacetic acid solution (at $3 \%$ by volume). The aqueous solution of the peptide was mixed with a saturated matrix solution (1:3 peptide/matrix) and air-dried. The monoisotopic molecular mass of the ion corresponding to the peptide of interest was determined by the ratio between $\mathrm{m} / \mathrm{z}$ peaks in the spread profile $(\mathrm{m} / \mathrm{z}$ ratio from 600 to 3,000). Additionally, interpretation of the MS/MS mass spectra

\footnotetext{
${ }^{1}$ http://blast.ncbi.nlm.nih.gov/Blast.cgi

${ }^{2}$ http://www.camp.bicnirrh.res.in/

${ }^{3}$ http://tcoffee.crg.cat/apps/tcoffee/do:mcoffee

${ }^{4}$ http://weblogo.berkeley.edu/logo.cgi
} 
TABLE 1 | Sequence of chemically synthesized peptides obtained from scorpion venom cDNA library sequencing.

\begin{tabular}{|c|c|c|c|c|}
\hline Peptide & Subfamily & UniProt entry & Sequence & Species \\
\hline ToAP2 & 3 & LT576030 & FFGTLFKLGSKLIPGVMKLFSKKKER & T. obscurus \\
\hline ToAP2S1 & 3 & & FFGTLFKLLSKLIPGLMKLFSKLLER-NH ${ }_{2}$ & Modified \\
\hline Con10 & 3 & C5J897 & FWSFLVKAASKILPSLIGGGDDNKSSS & O. cayaporum \\
\hline TOAP3 & 4 & $*$ & FIGMIPGLIGGLISAIK-NH2 & T. obscurus \\
\hline NDBP-4.23 & 4 & Q5G8B5/S6D3A7 & FLGMIPGLIGGLISAFK-NH2 2 & T. costatus; T. obscurus \\
\hline ToAP1 & 4 & LT576029 & FIGMIPGLIGGLISAFK-NH ${ }_{2}$ & T. obscurus \\
\hline ToAP4 & 4 & * & FFSLIPSLIGGLVSAIK-NH2 & T. obscurus \\
\hline NDBP-5.6 & 5 & P0C8W2 & FIFDLLKKLV & H. gertschi \\
\hline NDBP-5.7 & 5 & C5J886 & ILSAIWSGIKSLF-NH 2 & O. cayaporum \\
\hline NDBP-5.8 & 5 & C5J887 & GILGKIWEGVKSLI & O. cayaporum \\
\hline ToAcP & $* *$ & LT576031 & EEDDLLGFSEEDLKAIKEHRAKNA-NH 2 & T. obscurus \\
\hline
\end{tabular}

*Accession number recently requested; ** subfamily not designated. NDBP, non-disulfide-bridged peptide.

and de novo sequencing of peptides was performed using the FlexAnalysis 3.0 software (Bruker Daltonics, Germany). Throughout the experiment, the stability of each peptide was reevaluated using the same mass spectrometry parameters detailed above. Only samples containing more than $95 \%$ of the peptide (high purity) were used for biological experiments. Peptides were stored at $-20^{\circ} \mathrm{C}$ and dissolved in Milli-Q water before each experiment.

\section{In silico Analysis of Putative Secondary Structure and Peptides Physicochemical Properties}

The putative secondary structures and the $\alpha$-helix content (\%) were predicted using the software PHD as described

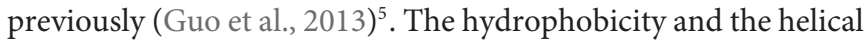
hydrophobic moment of the peptides were determined in the HeliQuest web server ${ }^{6}$. Other physicochemical properties were determined by ProtParam tool ${ }^{7}$ (Wilkins et al., 1999). Helical wheel projections were generated at the respective web server ${ }^{8}$.

\section{Fungal Strains and Growth Conditions}

Candida albicans strain SC 5314 (ATCC MYA-2876) was provided by Dr. Joshua Nosanchuk (New York, NY, USA). C. glabrata ATCC 90030, C. parapsilosis ATCC 22019, and C. tropicalis ATCC 750 were provided by Dr. Érika Kioshima (Universidade Estadual de Maringá, Paraná, Brazil). C. neoformans var. grubii strain H99 (serotype A, ATCC 208821) was provided by Dr. John Perfect (Durham, NC, USA). C. neoformans var. neoformans B3501 (serotype D, ATCC 34873) was obtained from ATCC (Manassas, VA, USA). All strains were stored as frozen stocks in $35 \%$ glycerol at $-80^{\circ} \mathrm{C}$. Before each experiment, all Candida spp. strains were grown in Sabouraud's dextrose broth overnight at $30^{\circ} \mathrm{C}$ with agitation. C. neoformans strains were grown in the same conditions for $24 \mathrm{~h}$. Fungal cells were collected by centrifugation, washed three times in

\footnotetext{
${ }^{5}$ https://npsa-prabi.ibcp.fr/cgi-bin/npsa_automat.pl?page=/NPSA/npsa_phd.html ${ }^{6}$ http://heliquest.ipmc.cnrs.fr/cgi-bin/ComputParamsV2.py

${ }^{7}$ http://web.expasy.org/protparam

${ }^{8}$ http://rzlab.ucr.edu/scripts/wheel/wheel.cgi
}

phosphate buffered saline (PBS) (137 mM NaCl, $2.7 \mathrm{mM} \mathrm{KCl}$, $\left.10 \mathrm{mM} \mathrm{Na}_{2} \mathrm{HPO}_{4}, 2 \mathrm{mM} \mathrm{KH} \mathrm{PO}_{4}\right)$ and inoculated in Roswell Park Memorial Institute (RPMI) 1640 medium supplemented with L-glutamine and buffered to $\mathrm{pH} 7.0$ with $165 \mathrm{mM} \mathrm{3-(N-}$ morpholino)propanesulfonic acid for experiments described below.

\section{Antifungal Assay}

In vitro antifungal assays were performed according to broth microdilution susceptibility test from Clinical and Laboratory Standards Institute (CLSI) M27-A3 guidelines with some modifications. Briefly, twofold serial dilutions of each peptide were prepared in 96-well polystyrene microplates to a final volume of $50 \mu \mathrm{L}$. Amphotericin B (Amp B; A2942, SigmaAldrich), a known antifungal drug, was used as a positive control. Final concentrations of each peptide and Amp B ranged from 100 to $0.78 \mu \mathrm{M}$ and 16 to $0.03 \mu \mathrm{g} / \mathrm{mL}$, respectively, except in tests with C. glabrata and C. parapsilosis, where the final peptide concentration ranged from 400 to $0.78 \mu \mathrm{M}$. In each plate, wells were included without peptide as a growth control. Then, $50 \mu \mathrm{L}$ of the adjusted inoculum in RPMI-1640 medium were added to each well to a final concentration of $2 \times 10^{3}$ cells $/ \mathrm{mL}$ for Candida spp. and $10^{4}$ cells $/ \mathrm{mL}$ for $C$. neoformans strains. The plates were incubated at $37^{\circ} \mathrm{C}$ for 24 and $48 \mathrm{~h}$, respectively. The strains of C. neoformans were also incubated with shaking (200 rpm). The minimum inhibitory concentration (MIC) was defined as the lowest AMP concentration that completely inhibited visible fungal growth at the end of the incubation period. The experiments were performed at least three times on separate dates.

\section{Hemolytic Assay}

Considering the potential use of the AMPs as treatment against pathogens, even if in a more distant future, some of their properties against host cells should be addressed. To achieve this goal, we have performed hemolytic assay to evaluate if these molecules are toxic or harmless to red blood cells. Further, we have also tested the possible cytotoxicity of those peptides against other mammalian cell types by following the cell viability score after treatment. The solution of human red blood cells was treated 
with the peptide at levels ranging from 100 to $0.78 \mu \mathrm{M}$. Whole human blood was collected from healthy donors in vials with ethylenediaminetetraacetic acid (EDTA). The red blood cells were separated by centrifugation and resuspended in PBS. After the centrifugation $\left(800 \mathrm{~g}, 5 \mathrm{~min}\right.$ at $\left.4 \pm 1^{\circ} \mathrm{C}\right)$ the supernatant was removed and the red blood cells pellet was resuspended to a $3 \%$ hematocrit in sterile water (considered as 100\% hemolysis) and PBS (taken as blank for spectrophotometric measurement). Fifty microliters of the $3 \%$ cell suspension in PBS were added to different final concentrations of the peptide (v/v) in a 96-well polystyrene microplate and then incubated for $1 \mathrm{~h}$ (Nahar et al., 2008; Zhao et al., 2009; Qi et al., 2010). The microplates were centrifuged and the supernatant was collected and analyzed at $540 \mathrm{~nm}$ using a microplate spectrophotometer. The percentage of hemolysis was calculated relative to the positive control as performed by Nahar et al. (2008). The procedures were approved by the Ethics Committee on Human Research of Faculty of Medicine/University of Brasília (UnB) and conform to FDA standards (UnBDoc no. 66704/2016).

\section{Cytotoxic Test Using Peritoneal Macrophages}

$\mathrm{BALB} / \mathrm{c}$ mice were injected with thioglycolate $72 \mathrm{~h}$ before peritoneal macrophages were harvested. They were diluted to a concentration of $10^{6}$ cell $/ \mathrm{mL}$ in RPMI-1640 supplemented with penicillin/streptomycin $(100 \mathrm{U} / \mathrm{mL}, 100 \mathrm{~g} / \mathrm{mL}), 2 \mathrm{mM}$ L-glutamine, $2 \mathrm{mM}$ non-essential amino acids, $1 \mathrm{mM}$ sodium pyruvate (all reagents from Sigma-Aldrich, St Louis, MO, USA) and $10 \%$ fetal bovine serum (FBS), and incubated in 96-well polystyrene microplates at $37^{\circ} \mathrm{C}, 5 \% \mathrm{CO}_{2}$ for $24 \mathrm{~h}$. The peptides were added then and cells were further incubated for $24 \mathrm{~h}$ as described previously (Cruz et al., 2005). Three independent experiments were performed. Cytotoxic activity was evaluated by the release of cytoplasmic enzyme lactate dehydrogenase due to cell lysis using the Cytotox kit (Promega). Briefly, at the end of the incubation period, supernatants were collected, the adhered cells were washed and the toxicity was determined according to the manufacturer's protocol. The procedures were approved by the Ethics Committee on Animal Research of Institute of Biology (UnBDOC 52657/2011)/University of Brasília (UnB).

\section{Effects of Peptides on Candida albicans Biofilms}

The effects of the peptides NDBP-4.23, ToAP1, ToAP2, and NDBP-5.7 on C. albicans biofilms were analyzed according to the protocol described by Pierce et al. (2008). Briefly, C. albicans SC $5314\left(10^{6}\right.$ cells $\left./ \mathrm{mL}\right)$ was grown on 96-well polystyrene microplates and $4 \mathrm{~h}$ after seeding the peptides or Amp B were added to assess their effects on the first step of biofilm formation, the initial cell adherence. After $24 \mathrm{~h}$ of treatment, biofilm formation was measured by the metabolic assay based on the reduction of 2,3-bis-(2-methoxy-4-nitro-5-sulfophenyl)2H-tetrazolium-5-carboxanilide (XTT). For the purpose of investigating effects of peptides on mature biofilms, the Candida cells were allowed to grow for $24 \mathrm{~h}$ prior to addition of the peptides or Amp B and the XTT assay was performed in the same way. All results were analyzed for statistical significance using analysis of variance (ANOVA) followed by Tukey post-test using GraphPad Prism 6 and expressed in terms of biofilm viability as XTT-readings percentage normalized by the control groups. Each compound was tested in triplicate and the experiments were performed at least twice on separate dates.

\section{Circular Dichroism}

Circular dichroism (CD) assays were carried out using Jasco J815 spectropolarimeter equipped with a Peltier-type temperature controller. Peptides $(0.2 \mathrm{mg} / \mathrm{mL})$ were analyzed in water at $37^{\circ} \mathrm{C}$ in absence or the presence of trifluoroethanol (TFE) (10, 30, and $50 \%$ ). The mean spectrum of three consecutive experiments was corrected for the baseline buffer contribution. The observed ellipticities were converted into molar ellipticity $([\theta])$ based on molecular mass per residue of $115 \mathrm{Da}$ (Adler et al., 1973). The $\alpha$ helix secondary structure content $(f \theta)$ was estimated considering the values of $[\theta]_{208} \mathrm{~nm}$ as a function of TFE concentration using the following equation (Greenfield and Fasman, 1969):

$$
f_{H}=\frac{\left([\theta]_{208}-4000\right)}{(-33000-4000)}
$$

\section{RESULTS}

\section{In silico Prediction of Major Physicochemical Properties and Secondary Structure of Peptides}

The primary structures of ToAP2, ToAP1, ToAP3, ToAP4, and ToAcP peptides from $T$. obscurus were used as queries on BLAST. Data analysis revealed that ToAP2 is similar to peptides previously described as belonging to NDBP subfamily 3 and to AMPs from ant venom (Figures 1A,B). ToAP1, ToAP3, and ToAP4 showed similarity to AMPs belonging to NDBP subfamily 4 (Figures 1C,D). ToAP4 also has $100 \%$ identity to putative AMP clone 6 from T. costatus [UniProt: Q5G8B3]. ToAcP did not show similarity to any AMPs described before and shares 90\% identity to Toxin Tp3 [UniProt: P0DL22], a peptide from Tityus pachyurus with no toxicity to mammalian cells and without known biological activity (Barona et al., 2006). The result of these analyses indicates that peptide ToAP2 belong to NDBP subfamily 3 and ToAP1, ToAP3, ToAP4 belongs to NDBP subfamily 4.

The results of in silico secondary structure and physicochemical property prediction for the peptides are summarized in Table 2. Except for ToAP2 and ToAcP, which have net charges at $\mathrm{pH} 7.0$ of +6 and -4 , respectively, all others showed a net charge of +1 . All peptides have a predicted helical content of at least $53.85 \%$ and, except for ToAcP, had positive hydrophobicity values, which means that in theory they are slightly hydrophobic. ToAP2S1, an analog from ToAP2, had different physicochemical parameters. Its net charge was reduced from +6 to +4 as a result of the substitution of two lysines for leucines; and both its hydrophobicity and hydrophobic moment were increased. ToAP2S1 also had its predicted helical content increased from 57.69 to $88.46 \%$ relative to its prototype ToAP2. 
A

TOAP2

Ponericin-W-like321

Ponericin-W-1ike 322

Css 54

Ponericin-W5

Pandinin 2

Ponericin-W2

Ponericin-W1

*Heterin-2

$\begin{array}{lll}\text { FFGTLFKLGSKLIPGVMKLFSKKKER } & 26 & 100 \\ \text { IFGSLFSLGSKLLPSVFKLFSRKK-Q } & 25 & 68.0 \\ \text { IFGSLFSLGSKLLPTVFKLFSRKK-Q } & 25 & 68.0 \\ \text { FFGSLLSLGSKLLPSVFKLFQRKK-E } & 25 & 68.0 \\ \text { FWGALIKGAAKLIPSVVGLFKKK--Q } & 24 & 54.2 \\ \text { FWGALAKGALKLIPSLFSSFSKKD-- } & 24 & 50.0 \\ \text { WLGSALKIGAKLLPSVVGLFQKKK-K } & 25 & 48.0 \\ \text { WLGSALKIGAKLLPSVVGLFKKKK-Q } & 25 & 48.0 \\ \text { FWGALAKGALKLIPSLVSSFTKKD-- } & 24 & 45.8\end{array}$

B

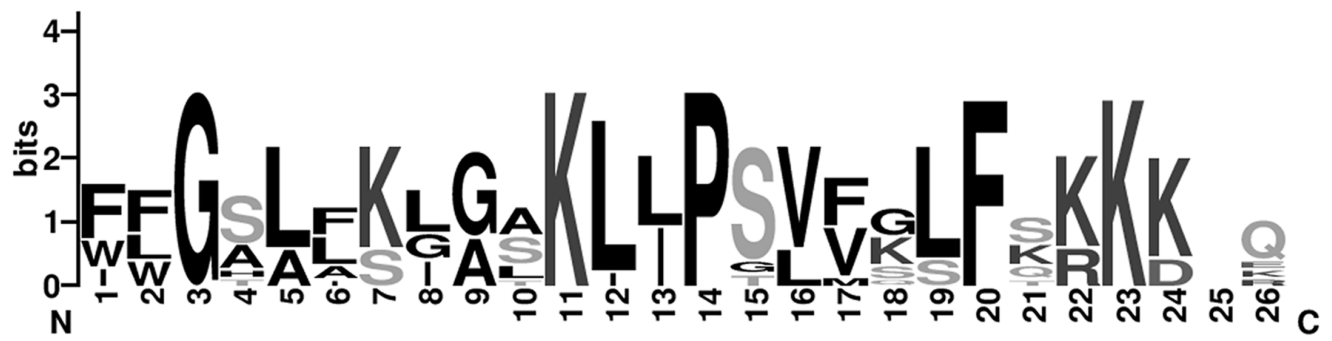

C

*ToAP1
*ToAP3
*NDBP-4.23/TsAP-2
*Mucroporin
*Stigmurin
*ToAP5/AP6_TITCO
*TsAP-1
*AamAP1
*Imcroporin
*AamAP2
*BmKb1
*AcrAP1

$\begin{array}{lll} & \text { a } a & \frac{\circ}{0} \\ \text {-FIGMIPGLIGGLISAFK } & 17 & 100 \\ \text {-FIGMIPGLIGGLISAIK } & 17 & 94.1 \\ \text {-FLGMIPGLIGGLISAFK } & 17 & 94.1 \\ \text {-LFGLIPSLIGGLVSAFK } & 17 & 70.6 \\ \text {-FFSLIPSLVGGLISAFK } & 17 & 70.6 \\ \text {-FFSLIPSLIGGLVSAIK } & 17 & 64.7 \\ \text {-FLSLIPSLVGGSISAFK } & 17 & 64.7 \\ \text { FLFSLIPHAIGGLISAFK } & 18 & 64.7 \\ \text {-FFSLLPSLIGGLVSAIK } & 17 & 58.8 \\ \text { FPFSLIPHAIGGLISAIK } & 18 & 58.8 \\ \text { FLFSLIPSAISGLISAFK } & 18 & 58.8 \\ \text { FLFSLIPHAISGLISAFK } & 18 & 58.8\end{array}$

D

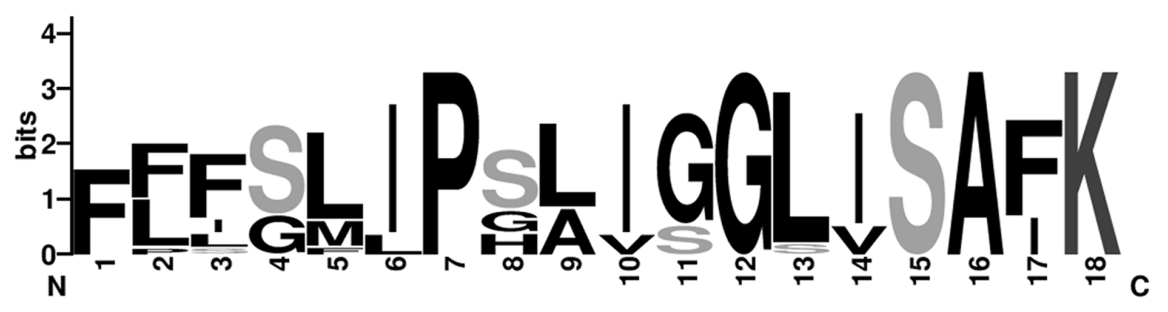

FIGURE 1 | Comparative analysis of ToAP2, ToAP1, ToAP3, ToAP4 against previously described AMPs. Conserved amino acid residues are marked bold. Asterisks indicate peptides with amidated C-termini. (A,B) Multiple sequence alignment of ToAP2 mature peptide with known AMPs from scorpion and ant venoms such as Ponericin-W-like 32.1 [UniProt: P0CI91], Ponericin-W-like 32.2 [UniProt: P0CI92], Css54 [UniProt: PODL41], Pandinin 2 [UniProt: P83240], Heterin-2 [UniProt: A0A0C4G5K0], Ponericin-W1 [UniProt: P82423], Ponericin-W2 [UniProt: P82424], and Ponericin-W5 [UniProt: P82427] and their consensus sequence logo. (C,D) Multiple sequence alignment of ToAP1 mature peptide with known antimicrobial peptides from scorpion venom such as NDBP-4.23 [UniProt: Q5G8B5/S6D3A7], Mucroporin [UniProt: B9UIY3], Imcroporin [UniProt: C7B247], Stigmurin [GenBank: JK483709], AP6_TITCO [UniProt: Q5G8B3], TsAP-1 [UniProt: S6CWV8], AamAP1 [UniProt: G8YYA5], AamAP2 [UniProt: G8YYA6], BmKb1 [UniProt: Q718F4], and AcrAP1 [UniProt: A0A0A116E7] and their consensus sequence logo. 
TABLE 2 | Peptide sequences, putative secondary structure, and physicochemical properties.

\begin{tabular}{|c|c|c|c|c|c|c|}
\hline Peptide & $\begin{array}{c}\text { Sequence and } \\
\text { secondary structure }\end{array}$ & Length & $\alpha$-helix (\%) & Hydrophobicity & Hydrophobic moment & Net charge \\
\hline ToAP2 & $\begin{array}{l}\text { FFGTLFKLGSKLIPGVMKLFSKKKER } \\
\text { ccchhhhcccchhhhhhhhhhhcccc }\end{array}$ & 26 & 57.69 & 0.443 & 0.460 & +6 \\
\hline ToAP2S1 & $\begin{array}{l}\text { FFGTLFKLLSKLIPGLMKLFSKLLER-NH }{ }_{2} \\
\text { cchhhhhhhhhhhhhhhhhhhhhhhc }\end{array}$ & 26 & 88.46 & 0.734 & 0.672 & +4 \\
\hline Con10 & 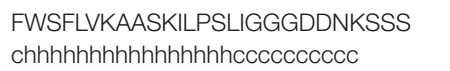 & 27 & 59.26 & 0.435 & 0.331 & +1 \\
\hline ToAP1 & $\begin{array}{l}\text { FIGMIPGLIGGLISAFK-NH } \\
\text { ccchhhhhhhhhhhccc }\end{array}$ & 17 & 64.71 & 0.906 & 0.597 & +1 \\
\hline ToAP3 & $\begin{array}{l}\text { FIGMIPGLIGGLISAIK-NH2 } \\
\text { cccchhhhhhhhhhhcc }\end{array}$ & 17 & 64.71 & 0.907 & 0.597 & +1 \\
\hline NDBP-4.23 & $\begin{array}{l}\text { FLGMIPGLIGGLISAFK-NH } 2 \\
\text { ccchhhhhhhhhhhhhc }\end{array}$ & 17 & 76.47 & 0.908 & 0.594 & +1 \\
\hline ToAP4 & $\begin{array}{l}\text { FFSLIPSLIGGLVSAIK-NH2 } \\
\text { cccchhhhhhhhhhhhc }\end{array}$ & 17 & 70.59 & 0.895 & 0.592 & +1 \\
\hline NDBP-5.6 & $\begin{array}{l}\text { FIFDLLKKLV } \\
\text { chhhhhhhcc }\end{array}$ & 10 & 70.00 & 0.895 & 0.715 & +1 \\
\hline NDBP-5.7 & $\begin{array}{l}\text { ILSAIWSGIKSLF-NH } \\
\text { ccchhhhchhhcc }\end{array}$ & 13 & 53.85 & 0.926 & 0.668 & +1 \\
\hline NDBP-5.8 & $\begin{array}{l}\text { GILGKIWEGVKSLI } \\
\text { chhhhhhhhhhhhc }\end{array}$ & 14 & 85.71 & 0.686 & 0.680 & +1 \\
\hline ToAcP & $\begin{array}{l}\text { EEDDLLGFSEEDLKAIKEHRAKNA-NH } \\
\text { ccccccccchhhhhhhhhhhhhcc }\end{array}$ & 24 & 54.17 & -0.016 & 0.248 & -4 \\
\hline
\end{tabular}

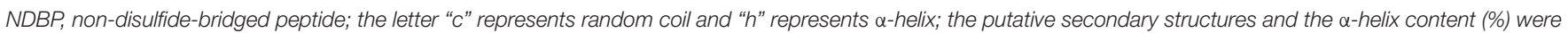

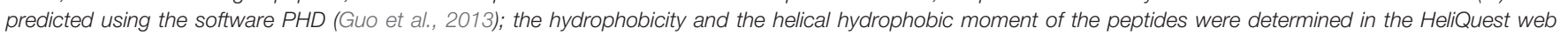
server; length and net charge properties were determined by ProtParam tool.

Helical wheel projections predict that ToAP2, ToAP2S1, ToAP1, ToAP3, and ToAP4, once adopting a helical conformation, are amphipathic peptides, thus presenting distinct hydrophobic and hydrophilic faces (Figure 2). ToAcP, however, presents only a hydrophilic face. The lack of a distinct hydrophobic face compromises its amphipathicity.

\section{Antimicrobial Assay}

Antifungal assays were performed against different species of Candida and C. neoformans (Table 3).

Seven peptides were active against Candida spp. and C. neoformans. ToAP2 and Con10, both from NDBP subfamily 3 , had antifungal activity against all strains tested with MICs values ranging from 3.12 to $200 \mu \mathrm{M}$ and 12.5 to $200 \mu \mathrm{M}$, respectively. Among peptides from NDBP subfamily 4, only ToAP4 has not shown antifungal activity in the tested concentrations (data not shown). The other peptides from this subfamily presented antimicrobial activity against all Candida spp. and C. neoformans in the same MIC range (6.25-200 $\mu \mathrm{M})$, except for C. glabrata, which is insensitive to them. C. glabrata is also resistant to all peptides from NDBP subfamily 5. Among those subfamily peptides, NDBP 5.7 presented antifungal activity with MIC values ranging from 12.5 to $25 \mu \mathrm{M}$ and NDBP 5.8 inhibited the growth of pathogens tested at concentrations ranging from 50 to $200 \mu \mathrm{M}$. NDBP-5.6 and ToAcP did not present antifungal activity in this assay (data not shown).

Since ToAP2 showed the lower MIC against all pathogens tested in this work, derivatives of its structure were produced in order to increase the $\alpha$-helical content. The modified peptide,
ToAP2S1 (Table 1) was synthesized and tested against two Candida species (C. albicans and C. glabrata) and C. neoformans H99. ToAP2S1 did not show antifungal activity in the tested concentrations (data not shown), demonstrating that the changes in peptide sequence abolished antifungal activity relative to the reference peptide.

Based on results from antimicrobial assay, we decided to proceed only with those peptides (at least one per family) that showed best antimicrobial activity.

\section{Hemolysis and Cytotoxicity Assays}

The hemolytic activities of peptides ToAP2, NDBP-4.23, ToAP1, and NDBP-5.7 were evaluated against human erythrocytes (Figure 3). ToAP2S1 was also tested to evaluate if it also has lost its hemolytic activity. NDBP-4.23 and ToAP1 might be considered of interest to future studies, because in all the tested concentrations their hemolysis curves were significantly lower than 50\% of hemolysis (Conlon et al., 2007; Thaker et al., 2011; Figures 3B,C). However, NDBP-5.7 presents a hemolysis percent higher than $50 \%$ in concentrations up to $50 \mu \mathrm{M}$ (Figure 3D). Comparing the original peptide ToAP2 and the modified ToAP2S1, the last one shows a higher hemolysis curve with concentrations up to $25 \mu \mathrm{M}$ while the ToAP2 maintained its curve above $50 \%$ of hemolysis (Figure 3A).

Toxicity to mammalian cells was further evaluated by assessing the viability of murine peritoneal macrophages in the presence of the peptides (Figure 4). The threshold of acceptable cytotoxicity was set at $50 \%$ viability as postulated elsewhere (Thaker et al., 2011; Zhao et al., 2012). In conformity with the 


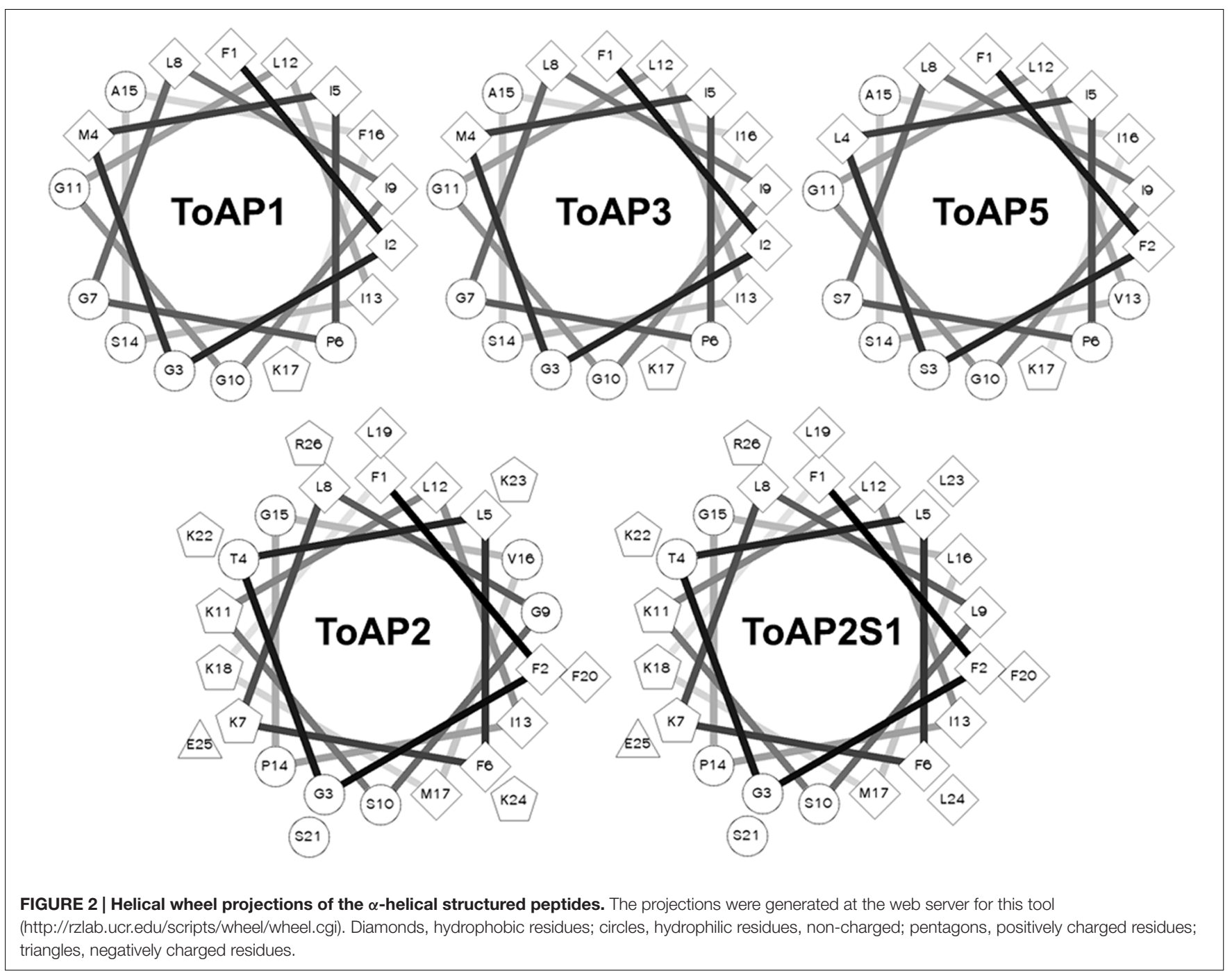

TABLE 3 | Inhibitory concentrations of different peptides against Candida spp. and two Cryptococcus neoformans strains.

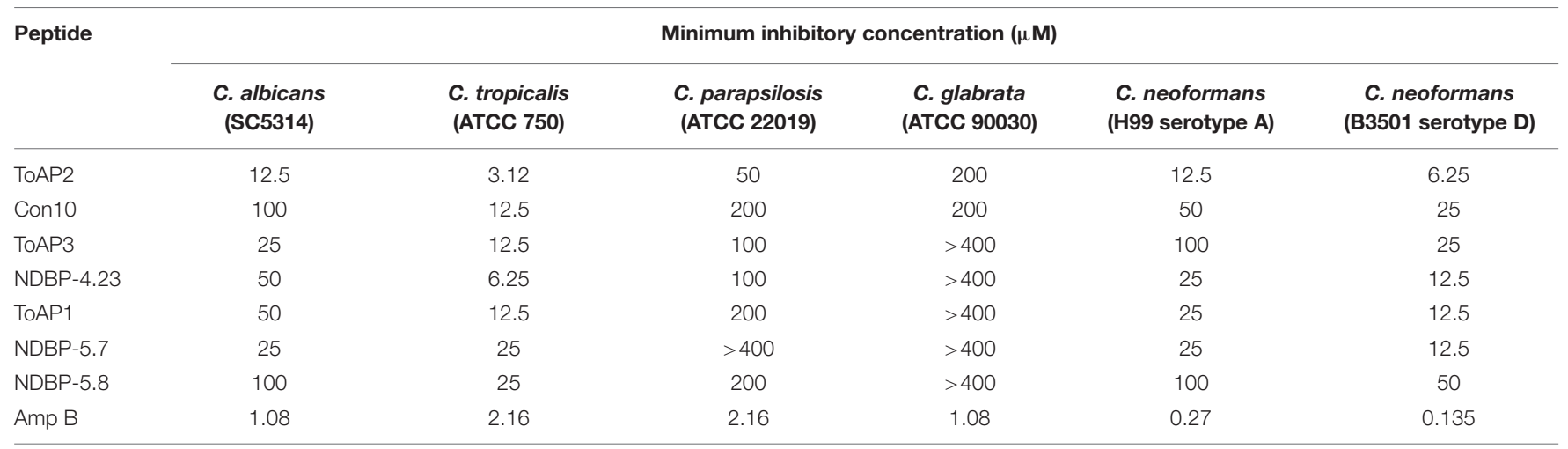

NDBP, non-disulfide-bridged peptide; $A m p B$, amphotericin $B$. The values of $0.135,0.27,1.08$ and 2,16 $\mu M$ of Amp B are equivalent to $0.125,0,25,1$ and $2 \mu \mathrm{g} / \mathrm{mL}$ of Amp $B$ respectively.

hemolytic test, ToAP2 and NDBP-4.23 in concentrations below 6.25 and $25 \mu \mathrm{M}$, respectively, have shown low cytotoxicity (Figures 4A-C). For ToAP1 and NDBP-5.7, peritoneal macrophages displayed higher viability in the whole range of peptide concentrations (Figures 4B-D). The difference in the hemolytic curves between ToAP2 and its analog (ToAP2S1) could be explained by the higher hydrophobicity of ToAP2S1 (Table 2) and consequent tendency to self-associate. Chen et al. 
A

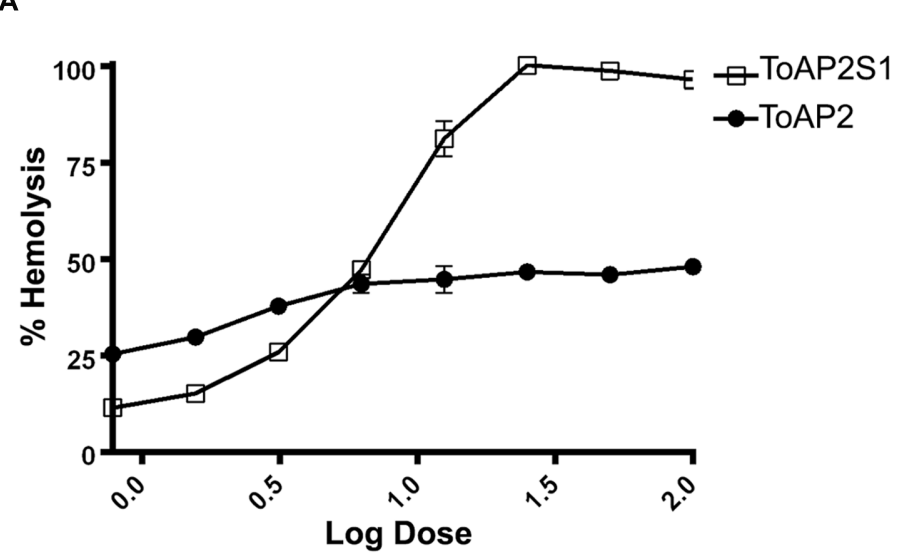

C

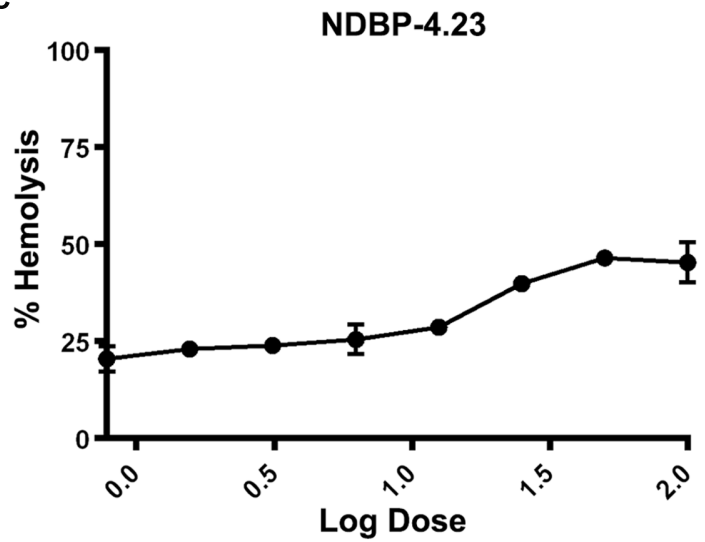

B

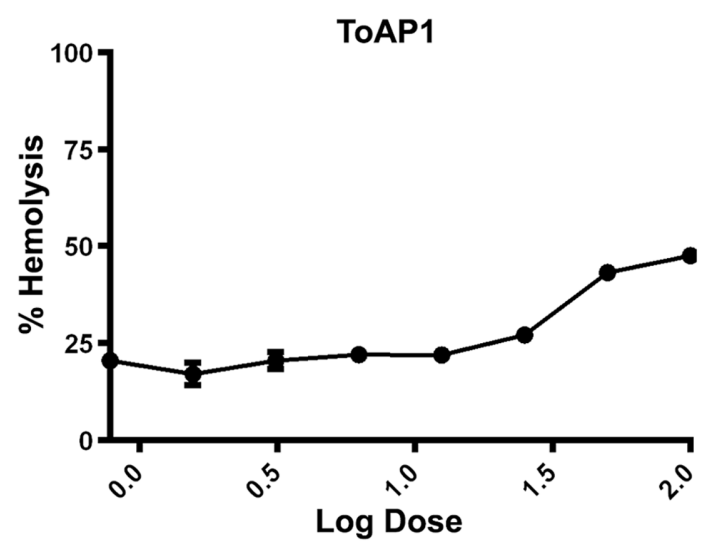

D

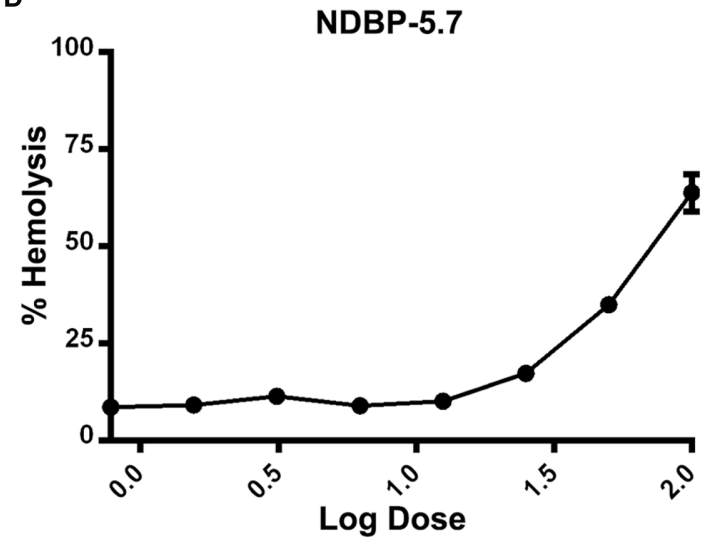

FIGURE 3 | Hemolytic activity of peptides against human erythrocytes. (A) ToAP2 and ToAP2S1, (B) ToAP1, (C) NDBP-4.23, and (D) NDBP-5.7.

(2007) demonstrated that there is an optimal hydrophobicity window for AMPs, below which antimicrobial activity can be lost and above which self-association becomes highly likely. Peptide aggregation prevents penetration through the capsule and cell wall of microorganisms (Jiang et al., 2008). However, the higher hydrophobicity does not affect their activity on the eukaryotic membrane (Chen et al., 2007), which explains the lower antifungal activity and the higher hemolytic activity of the modified ToAP2S1, respectively.

\section{Effects of the Peptides on Candida albicans Biofilms}

We visualized C. albicans biofilms at 4 and 24 h by fluorescence microscopy using uvitex $2 \mathrm{~B}$, which binds chitin in the fungal cell wall, and they exhibited typical features of mature biofilms, including a basal layer of yeast cells and a thicker layer of yeast and hyphae cells (Supplementary Material). This structure was very similar to the morphology of C. albicans biofilms presented in other works in the literature (Pierce et al., 2014, 2015). Additionally, the inhibition values of biofilms by Amp B were similar to those found by Ramage et al. (2001, 2002).

The effects of ToAP2, NDBP-4.23, ToAP1, and NDBP-5.7 on $C$. albicans biofilms were evaluated on the initial adherence step (Figure 5A) and on the mature biofilm (Figure 5C). As a control, the effect of Amp B was also shown at both time points (Figures 5B,D), with a reduction of at least $80 \%$ in biofilm viability at $0.25 \mu \mathrm{g} / \mathrm{mL}$ for the initial adherence and $2 \mu \mathrm{g} / \mathrm{mL}$ for the three-dimensional architecture. All the peptides were active against biofilm formation, albeit at a higher concentration compared to what was observed against planktonic cells $(100 \mu \mathrm{M}$ for the initial adherence and $400 \mu \mathrm{M}$ for the three-dimensional architecture). ToAP2 was the most active peptide at the two different stages of biofilm formation, with a lower effective concentration than the others $(25 \mu \mathrm{M}$ for the initial adherence and $200 \mu \mathrm{M}$ for the three-dimensional architecture).

\section{Circular Dichroism}

The secondary structures of native (ToAP2) and modified (ToAP2S1) peptides were assessed by CD spectroscopy. FAR-UV $\mathrm{CD}$ spectra of ToAP2 in water at $37^{\circ} \mathrm{C}$ revealed a typical disordered structural pattern (Figure 6A). At increasing concentrations of 10,30 , and $50 \%$ TFE (v/v), a red shift from 200 to 208 and $222 \mathrm{~nm}$ and increased negative dichroic signals were observed (Figure 6A). These results show that ToAP2 lacks secondary structure in aqueous environments 
A

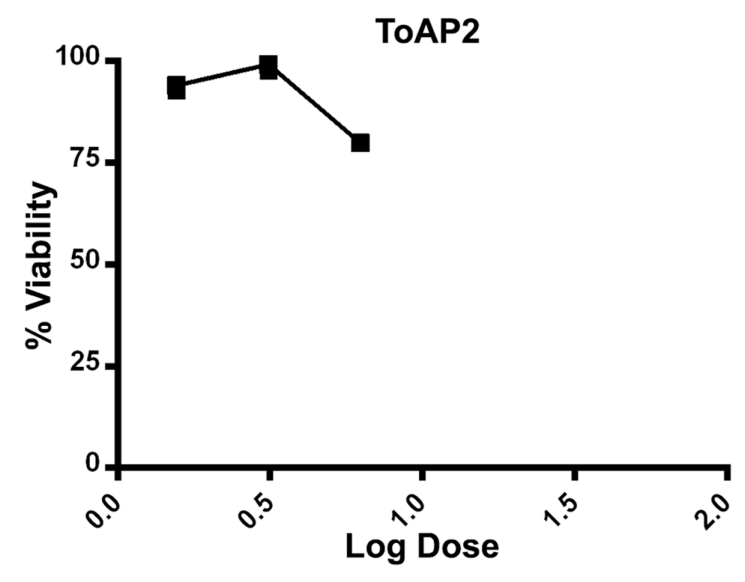

C

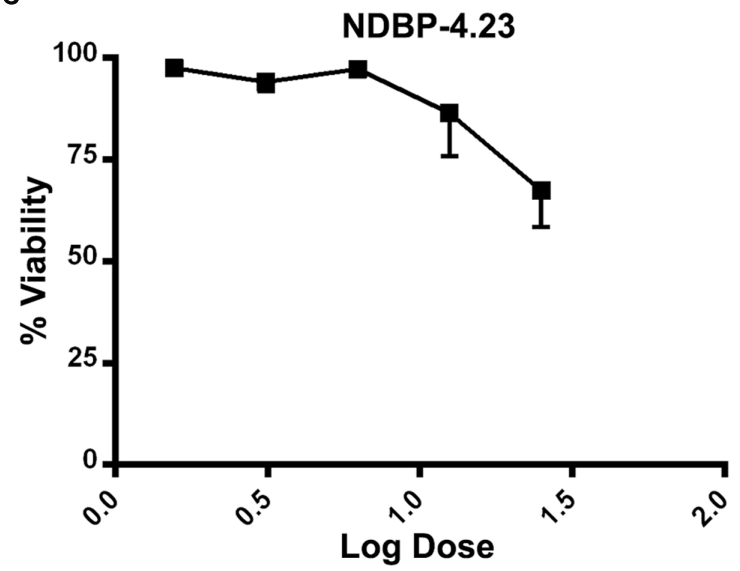

B

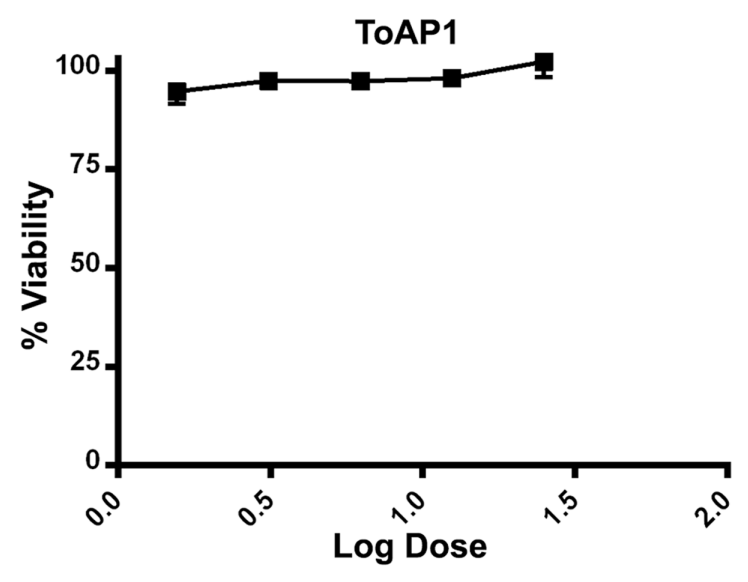

D

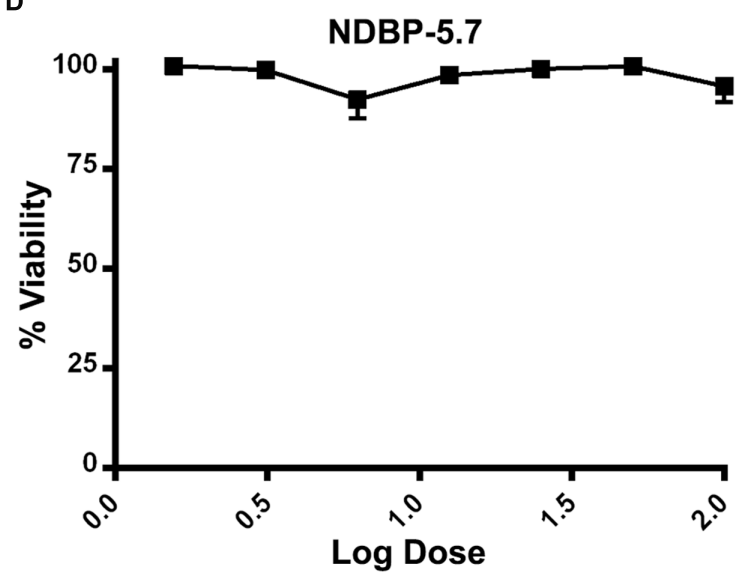

FIGURE 4 | Cytotoxicity of peptides against peritoneal macrophages of BALB/c mice. (A) ToAP2, (B) ToAP1, (C) NDBP-4.23, and (D) NDBP-5.7.

and has a tendency to adopt an $\alpha$-helical pattern at aqueous environments in the present of the co-solvent TFE (Table 4). In contrast, an $\alpha$-helical conformation was observed for the modified peptide ToAP2S1 in water at $37^{\circ} \mathrm{C}$ even in the absence of TFE. In the presence of 10, 30, and 50\% TFE, intense negative dichroic bands at 208 and $222 \mathrm{~nm}$ were observed (Figure 6B), which are compatible with higher $\alpha$-helix content (Table 4). Fractional helicity of peptides in water and TFE environments was calculated considering the molar ellipticity at $208 \mathrm{~nm}$ (Table 4). There was an increased $\alpha$-helix content for both peptides as a function of TFE, with ToAP2S1 presenting approximately $17 \%$ of $\alpha$-helix in water in the absence of the co-solvent.

\section{DISCUSSION}

We have witnessed a steady increase in the incidence of systemic fungal diseases in the last decades, partially due to medical advances and the rise of immunosuppressive diseases. Although antifungal therapy is somewhat efficient, there are only four classes of agents, many of which have significant side effects.
In addition, there is an increasing number of fungal species with natural or acquired resistance to these drugs. For instance, the most recent class of antifungals, the echinocandins, was discovered in the seventies and only became available for clinical therapy in 2002. Since then, the search for new antifungal targets and potential drugs for more efficient and less toxic treatments has been an ongoing work. AMPs are attractive alternatives as antifungal drugs and here we describe seven scorpion venomderived peptides with promising antimicrobial activity against Candida spp. and/or C. neoformans strains, all of which are major fungal pathogens.

Regardless of the strain, ToAP2, the most cationic peptide, showed the lowest inhibitory concentrations in our tests. ToAP2 and Con10 exhibited sequence similarity to Pandinin 2, for which anti-C. albicans activity has been described with a MIC of 19.1 $\mu \mathrm{M}$ (Corzo et al., 2001). In contrast, while ToAP2 presented MIC values around this range, Con 10 showed much higher values for $C$. albicans and most of the other tested strains. Despite the similarity, Con10 has lower net positive charge $(+1)$ than Pandinin $2(+3)$. Conversely, ToAP2 physicochemical properties are more similar to those of Pandinin 2: its net positive charge is +6 . Several studies have shown that analog of AMPs with 
A

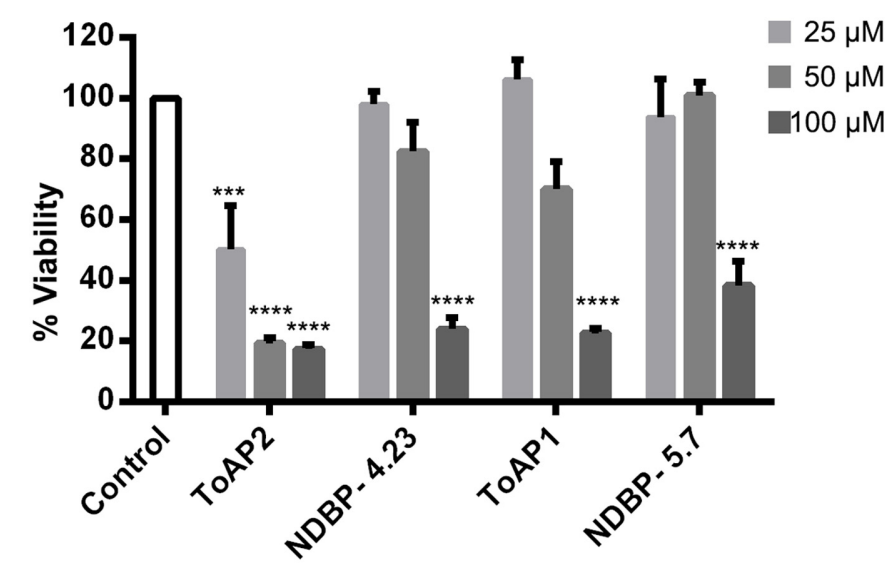

C

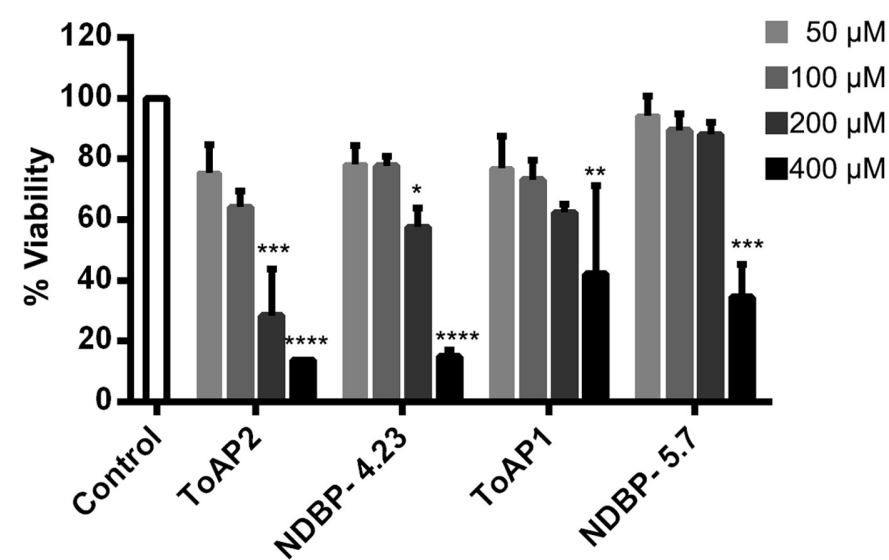

B

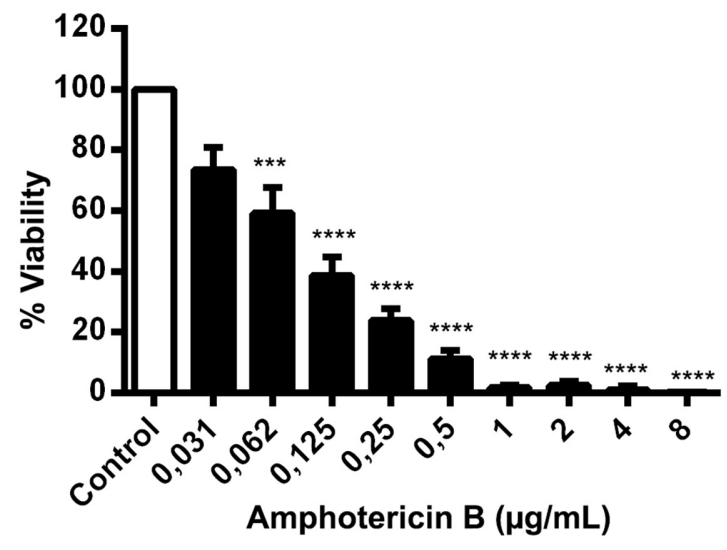

D

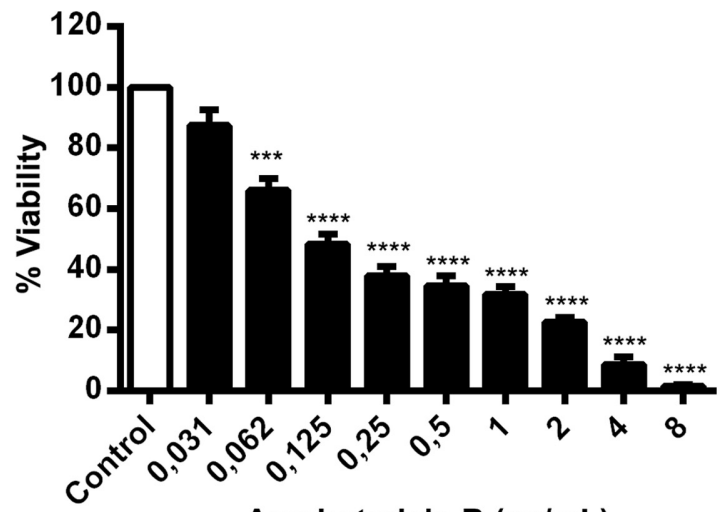

Amphotericin B $(\mu \mathrm{g} / \mathrm{mL})$

FIGURE 5 | Effects of the peptides ToAP2, NDBP-4.23, ToAP1, NDBP-5.7, and amphotericin B on C. albicans biofilm formation. Effects of the peptides (A) and Amp B (B) on the initial adherence and effects of the peptides (C) and Amp B (D) on the mature stage. Results are expressed in terms of biofilm viability as XTT-reduction assay readings percentage, normalized by the control groups. The experiments were performed at least twice on different days. Statistical analyses: ANOVA and Turkey post-test $\left({ }^{* * *} P \leq 0.0001 ;{ }^{* * *} P \leq 0.001 ;{ }^{*} P \leq 0.01 ;{ }^{*} P \leq 0.05\right)$. Mean $\pm \mathrm{SEM}$.

amino acids substitutions to increase positive net charge had better antifungal activity (Nikawa et al., 2004), which may explain the poor antifungal activity of Con 10 relative to ToAP2 and Pandinin 2.

We also analyzed the secondary structures of the peptides in water and in a mimetic membrane environment (aqueous co-solvent TFE) by CD spectroscopy. The FAR-UV CD spectra showed that ToAP2 and its modified version ToAP2S1 have typical disordered and $\alpha$-helical structures in water at $37^{\circ} \mathrm{C}$, respectively. There was an increase in $\alpha$-helix content for both peptides as a function of TFE concentration (Table 4), indicating the potential of these molecules to interact with the cellular membrane, a classical feature of $\alpha$-helical AMPs. Stability assays also showed that the non-modified peptide presented lower $\alpha$-helix content and lower stability than the modified peptide. These observations may indicate that net charge is an important parameter for antifungal activity as well as to the conformation changes induced by the interaction with the fungal membrane.
ToAP1 and ToAP3 share similarity with AamAP1, AamAP2, and AcrAP1 (Figure 1), peptides that have already been documented as having anti-C. albicans activity (Almaaytah et al., 2012; Du et al., 2014). Interestingly, ToAP1 and ToAP3 only differ at one residue at position 16 , respectively a Phe and an Ile. While ToAP3 has better anti-Candida spp. activity, ToAP1 showed better activity against C. neoformans (Table 3 ). This result suggests that Phe16 in ToAP1 could be essential for antiC. neoformans activity. The lack of activity of ToAP4 against the fungal strains tested in our assay condition is worth noting, in spite of its $82.3 \%$ identity with Stigmurin (Figure 1), a peptide from Tityus stigmurus that inhibits the growth of C. albicans and C. glabrata with MIC values of $34.8 \mu \mathrm{M}$ and $69.5 \mu \mathrm{M}$, respectively (de Melo et al., 2015). This difference could be due to different methods used to evaluate antifungal activity or the difference in sequence itself. More studies are needed to evaluate this.

NDBP-5.7 and NDBP-5.8 showed high similarity to IsCT, IsCT2, and Patinin3, peptides with antifungal activity against C. albicans and C. tropicalis (Dai et al., 2002; Zeng et al., 
A

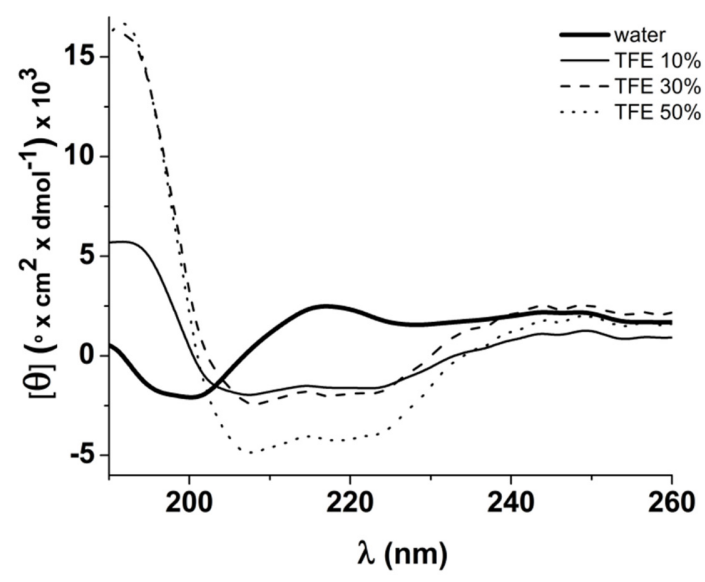

B

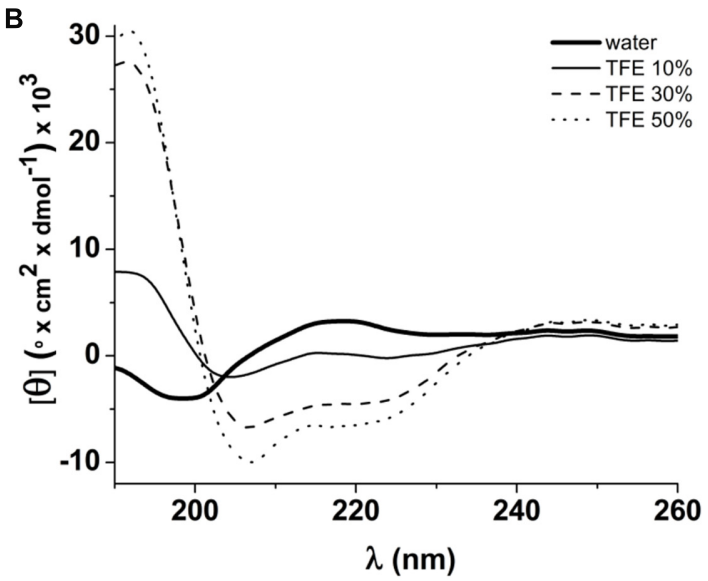

FIGURE 6 | FAR-UV CD spectra of peptides in water and 10, $30,50 \%$

TFE. (A) Spectra of ToAP2 presenting a red shift from $200 \mathrm{~nm}$ to 208 and $222 \mathrm{~nm}$ in the presence of TFE; (B) Spectra of ToAP2S1 showing an increase of the dichroic signals at 208 and $222 \mathrm{~nm}$ from water to TFE.

TABLE $4 \mid \alpha$-Helix content (\%) of peptides in water, and TFE at 10,30 , and $50 \%$.

\begin{tabular}{lcc}
\hline Solvent & \multicolumn{2}{c}{$\alpha$-Helix content (\%) of peptides } \\
\cline { 2 - 3 } & ToAP2 & ToAP2S1 \\
\hline Water & 9.8 & 16.5 \\
TFE 10\% & 12.9 & 22.9 \\
TFE 30\% & 20.8 & 24.3 \\
TFE 50\% & 25.8 & 24.7 \\
\hline
\end{tabular}

2013). Considering that the C-terminal amidation modifies the net positive charge and stabilizes peptide structure, improving antimicrobial activity (Huang et al., 2010), the lack of this chemical group may explain the lower activity of NDBP5.8 against the tested microorganisms (Tables 2 and 3). By its turn, the lack of antifungal activity of ToAcP probably could be explained by its net negative charge, which causes electrostatic repulsion from the microbial plasma membrane (van der Weerden et al., 2013).
Among the tested Candida species, C. glabrata was the most resistant, with inhibitory concentrations higher than $400 \mu \mathrm{M}$ for all peptides. This result is in accordance with the literature describing the high intrinsic resistance shown by this species to most antifungal drugs, as well as to Histatin 5, one of the best candidacidal peptides already described (Sobel, 2006; Tati et al., 2013; Rodrigues et al., 2014). Conversely, C. tropicalis was the most susceptible organism among Candida species. As shown in Table 3, the AMPs exhibited their lowest inhibitory concentrations against $C$. tropicalis, in contrast with its described high virulence, associated infection mortality rates, and resistance to amphotericin B (CLSI M27-A3 protocol (Colombo et al., 2007). Consequently, the peptides tested in this work are promising candidates for the development of treatments for C. tropicalis infection.

With regard to the effects of AMPs against C. neoformans, the B3501 strain (serotype D) was more sensitive to the scorpion peptides than the H99 strain (serotype A). This is in accordance with the previously described higher susceptibility of this serotype to amphotericin B (Thompson et al., 2009). C. neoformans has a negatively charged polysaccharide capsule that is one of the most important virulence factors of this yeast (McFadden et al., 2006). Its thickness varies according to strain, with strain B3501 presenting a thicker capsule than H99 under non-inducing conditions. Therefore, it is possible that the capsule exerts an electrostatic attraction effect on cationic AMPs, which may explain the higher susceptibility of strain B3501. Similarly, susceptibility of C. neoformans to polymyxin B was previously reported to be dependent on fungal capsule thickness (Zhai and Lin, 2013).

In addition to the effects on planktonic cells described above, we also analyzed their action against $C$. albicans biofilms. Biofilms represent a great health concern due to their intrinsic resistance to antimicrobial treatment and to the patient immune response. The resistance involves different factors like overexpression of drug resistance genes and impairment of drug penetration due the thickness of the extracellular matrix. All peptides tested (ToAP2, NDBP-4.23, ToAP1, and NDBP-5.7) reduced biofilm on both the initial cell adherence stage and the mature phase, albeit at higher concentration ranges relative to planktonic cells, which holds true for all antimicrobials. Again, ToAP2 was the most active peptide at the two different stages of biofilm formation, presenting a lower effective concentration than the other peptides $(25 \mu \mathrm{M}$ for the initial adherence and $200 \mu \mathrm{M}$ for the three-dimensional architecture). These results are encouraging, since the peptides showed an antifungal effect in different phases of the biofilm process with lower concentrations than expected for prospective antifungals (100-1,000 times higher than concentrations used against planktonic cells (Pierce et al., 2008). Furthermore, hemolysis and cytotoxicity assays showed promising results regarding the selective toxicity of the tested peptides. Most of the tested peptides can be considered of interest for future studies, as they caused hemolysis of less than $50 \%$ of erythrocytes and more than $50 \%$ of murine peritoneal macrophages remained viable in their presence.

In summary, we described seven scorpion venom-derived AMPs with antifungal activity against cells of Candida spp. and 
C. neoformans and against C. albicans biofilms, including two novel molecules. This is the first report of scorpion-derived AMPs against $C$. neoformans and our results underscore the potential of scorpion-venom as a source of antimicrobials. The observed effects of the described peptides during and after C. albicans biofilm formation highlight the antimicrobial potential of these molecules in the face of the huge impact of biofilm-derived infections in hospitalized patients. Further characterization of their mechanisms of action and interaction with available antifungals, followed by molecular optimization to reduce their toxicity to host cells and increase antimicrobial activity are need to fully clarify their real potential as antifungals.

\section{AUTHOR CONTRIBUTIONS}

FG and NV designed and carried out all AMP screening experiments and characterization of their antifungal properties. $\mathrm{KS}, \mathrm{MR}, \mathrm{PC}, \mathrm{AT}$, and $\mathrm{AB}$ designed and carried out the hemolysis and cytotoxicity assays. AA and SF contributed to CD experiments. OF contributed to MS experiments. MO, NV, FG, PA, IS-P, and LD contributed in the biofilm assays. AN supervised the biofilm microscopy analysis. ES selected the AMPs to be used in this work, contributed to chemical peptide synthesis and design of modified peptides. MM carried out peptide sequence, purity, and stability assessments (MS assays), contributed to antimicrobial assays and oversaw statistical analysis. PA and IS-P supervised all work. FG, NV, KS, AB, SF, PA, and IS-P contributed in the writing and revision of the manuscript. LD, OF, ES, and $\mathrm{MM}$ also contributed to the final revision of the manuscript. All authors read and approved the final version of the manuscript.

\section{REFERENCES}

Adler, A. J., Greenfield, N. J., and Fasman, G. D. (1973). Circular dichroism and optical rotatory dispersion of proteins and polypeptides. Methods Enzymol. 27, 675-735. doi: 10.1016/S0076-6879(73)27030-1

Almaaytah, A., and Albalas, Q. (2014). Scorpion venom peptides with no disulfide bridges: a review. Peptides 51, 35-45. doi: 10.1016/j.peptides.2013.10.021

Almaaytah, A., Zhou, M., Wang, L., Chen, T., Walker, B., and Shaw, C. (2012). Antimicrobial/cytolytic peptides from the venom of the North African scorpion, Androctonus amoreuxi: biochemical and functional characterization of natural peptides and a single site-substituted analog. Peptides 35, 291-299. doi: 10.1016/j.peptides.2012.03.016

Arendrup, M. C. (2013). Candida and candidaemia. Susceptibility and epidemiology. Dan. Med. J. 60:B4698.

Armstrong-James, D., Meintjes, G., and Brown, G. D. (2014). A neglected epidemic: fungal infections in HIV/AIDS. Trends Microbiol. 22, 120-127. doi: 10.1016/j.tim.2014.01.001

Barona, J., Batista, C. V., Zamudio, F. Z., Gomez-Lagunas, F., Wanke, E., Otero, R., et al. (2006). Proteomic analysis of the venom and characterization of toxins specific for $\mathrm{Na}+$ - and $\mathrm{K}+$-channels from the Colombian scorpion Tityus pachyurus. Biochim. Biophys. Acta 1764, 76-84. doi: 10.1016/j.bbapap.2005.08.010

Chen, Y., Guarnieri, M. T., Vasil, A. I., Vasil, M. L., Mant, C. T., and Hodges, R. S. (2007). Role of peptide hydrophobicity in the mechanism of action of alphahelical antimicrobial peptides. Antimicrob. Agents Chemother. 51, 1398-1406. doi: 10.1128/AAC.00925-06

Colombo, A. L., Guimaraes, T., Silva, L. R., de Almeida Monfardini, L. P., Cunha, A. K., Rady, P., et al. (2007). Prospective observational study of candidemia

\section{FUNDING}

This study was supported by research funding by the National Council of Technological and Scientific Development (CNPq) and the Research Support Foundation of the Federal District (FAP-DF; grant numbers: PRONEX 193.000.571/2009; Rede Centro-Oeste 561212/2010-4 and 193.000.477/2011).

\section{ACKNOWLEDGMENTS}

We are grateful to the graduate programs in Molecular Biology (CEL/IB/UnB) and Molecular Pathology (FM/UnB) for all support and $\mathrm{CNPq}$ and CAPES for fellowships awarded to the graduate students FG, NV, KS, and AA. LD was supported by a postdoctoral fellowship from $\mathrm{CNPq}$. We extend our gratitude to all colleagues of the INOVATOXIN network ("Innovation with venoms from animals from the Brazilian Midwest: therapeutic applications, toxicology and bioprospection"), for all valuable information. We thank Ana Marisa Fusco-Almeida (UNESPAraraquara) for the kind donation of Concanavalin A conjugated to Alexa Fluor 488 (CAAF; Molecular Probes, USA). We thank Dr. Cynthia Kyaw for helpful suggestions. We are grateful to Dr. Hugo Costa Paes for revising the manuscript.

\section{SUPPLEMENTARY MATERIAL}

The Supplementary Material for this article can be found online at: http://journal.frontiersin.org/article/10.3389/fmicb. 2016.01844/full\#supplementary-material

in Sao Paulo, Brazil: incidence rate, epidemiology, and predictors of mortality. Infect. Control Hosp. Epidemiol. 28, 570-576. doi: 10.1086/513615

Conlon, J. M., Al-Dhaheri, A., Al-Mutawa, E., Al-Kharrge, R., Ahmed, E., Kolodziejek, J., et al. (2007). Peptide defenses of the Cascades frog Rana cascadae: implications for the evolutionary history of frogs of the Amerana species group. Peptides 28, 1268-1274. doi: 10.1016/j.peptides.2007.03.010

Corzo, G., Escoubas, P., Villegas, E., Barnham, K. J., He, W., Norton, R. S., et al. (2001). Characterization of unique amphipathic antimicrobial peptides from venom of the scorpion Pandinus imperator. Biochem. J. 359(Pt 1), 35-45. doi: 10.1042/bj3590035

Cruz, A. H., Mendonca, R. Z., and Petricevich, V. L. (2005). Crotalus durissus terrificus venom interferes with morphological, functional, and biochemical changes in murine macrophage. Mediators Inflamm. 2005, 349-359. doi: 10.1155/MI.2005.349

Dai, L., Corzo, G., Naoki, H., Andriantsiferana, M., and Nakajima, T. (2002). Purification, structure-function analysis, and molecular characterization of novel linear peptides from scorpion Opisthacanthus madagascariensis. Biochem. Biophys. Res. Commun. 293, 1514-1522. doi: 10.1016/S0006-291X(02)00423-0

de Melo, E. T., Estrela, A. B., Santos, E. C., Machado, P. R., Farias, K. J., Torres, T. M., et al. (2015). Structural characterization of a novel peptide with antimicrobial activity from the venom gland of the scorpion Tityus stigmurus: Stigmurin. Peptides 68, 3-10. doi: 10.1016/j.peptides.2015.03.003

Diego-Garcia, E., Batista, C. V., Garcia-Gomez, B. I., Lucas, S., Candido, D. M., Gomez-Lagunas, F., et al. (2005). The Brazilian scorpion Tityus costatus Karsch: genes, peptides and function. Toxicon 45, 273-283. doi: 10.1016/j.toxicon.2004.10.014

Diekema, D., Arbefeville, S., Boyken, L., Kroeger, J., and Pfaller, M. (2012). The changing epidemiology of healthcare-associated candidemia 
over three decades. Diagn. Microbiol. Infect. Dis. 73, 45-48. doi: 10.1016/j.diagmicrobio.2012.02.001

Du, Q., Hou, X., Ge, L., Li, R., Zhou, M., Wang, H., et al. (2014). Cationicityenhanced analogues of the antimicrobial peptides, AcrAP1 and AcrAP2, from the venom of the scorpion, Androctonus crassicauda, display potent growth modulation effects on human cancer cell lines. Int. J. Biol. Sci. 10, 1097-1107. doi: $10.7150 /$ ijbs. 9859

Fanning, S., and Mitchell, A. P. (2012). Fungal biofilms. PLoS Pathog. 8:e1002585. doi: 10.1371/journal.ppat.1002585

Finkel, J. S., and Mitchell, A. P. (2011). Genetic control of Candida albicans biofilm development. Nat. Rev. Microbiol. 9, 109-118. doi: 10.1038/nrmicro2475

Greenfield, N., and Fasman, G. D. (1969). Computed circular dichroism spectra for the evaluation of protein conformation. Biochemistry 8, 4108-4116. doi: 10.1021/bi00838a031

Guerrero-Vargas, J. A., Mourao, C. B., Quintero-Hernandez, V., Possani, L. D., and Schwartz, E. F. (2012). Identification and phylogenetic analysis of Tityus pachyurus and Tityus obscurus novel putative $\mathrm{Na}+-$ channel scorpion toxins. PLOS ONE 7:e30478. doi: 10.1371/journal.pone. 0030478

Guo, X., Ma, C., Du, Q., Wei, R., Wang, L., Zhou, M., et al. (2013). Two peptides, TsAP-1 and TsAP-2, from the venom of the Brazilian yellow scorpion, Tityus serrulatus: evaluation of their antimicrobial and anticancer activities. Biochimie 95, 1784-1794. doi: 10.1016/j.biochi.2013.06.003

Hancock, R. E., and Sahl, H. G. (2006). Antimicrobial and host-defense peptides as new anti-infective therapeutic strategies. Nat. Biotechnol. 24, 1551-1557. doi: $10.1038 / \mathrm{nbt} 1267$

Harrison, P. L., Abdel-Rahman, M. A., Miller, K., and Strong, P. N. (2014). Antimicrobial peptides from scorpion venoms. Toxicon 88, 115-137. doi: 10.1016/j.toxicon.2014.06.006

Huang, Y., Huang, J., and Chen, Y. (2010). Alpha-helical cationic antimicrobial peptides: relationships of structure and function. Protein Cell 1, 143-152. doi: 10.1007/s13238-010-0004-3

Jiang, Z., Vasil, A. I., Hale, J. D., Hancock, R. E., Vasil, M. L., and Hodges, R. S. (2008). Effects of net charge and the number of positively charged residues on the biological activity of amphipathic alpha-helical cationic antimicrobial peptides. Biopolymers 90, 369-383. doi: 10.1002/bip.20911

Martinez, L. R., and Casadevall, A. (2015). Biofilm formation by Cryptococcus neoformans. Microbiol. Spectr. 3, MB-0006-2014. doi: 10.1128/microbiolspec.MB-0006-2014

Mayer, F. L., Wilson, D., and Hube, B. (2013). Candida albicans pathogenicity mechanisms. Virulence 4, 119-128. doi: 10.4161/viru.22913

McFadden, D. C., De Jesus, M., and Casadevall, A. (2006). The physical properties of the capsular polysaccharides from Cryptococcus neoformans suggest features for capsule construction. J. Biol. Chem. 281, 1868-1875. doi: 10.1074/jbc.M509465200

Mikulska, M., Del Bono, V., Ratto, S., and Viscoli, C. (2012). Occurrence, presentation and treatment of candidemia. Expert Rev. Clin. Immunol. 8, 755-765. doi: 10.1586/eci.12.52

Mookherjee, N., and Hancock, R. E. (2007). Cationic host defence peptides: innate immune regulatory peptides as a novel approach for treating infections. Cell Mol. Life Sci. 64, 922-933. doi: 10.1007/s00018-007-6475-6

Nahar, M., Mishra, D., Dubey, V., and Jain, N. K. (2008). Development, characterization, and toxicity evaluation of amphotericin B-loaded gelatin nanoparticles. Nanomedicine 4, 252-261. doi: 10.1016/j.nano.2008. 03.007

Nikawa, H., Fukushima, H., Makihira, S., Hamada, T., and Samaranayake, L. P. (2004). Fungicidal effect of three new synthetic cationic peptides against Candida albicans. Oral Dis. 10, 221-228. doi: 10.1111/j.1601-0825.2004. 01010.x

Ortiz, E., Gurrola, G. B., Schwartz, E. F., and Possani, L. D. (2015). Scorpion venom components as potential candidates for drug development. Toxicon 93, 125-135. doi: 10.1016/j.toxicon.2014.11.233

Pan, W., Khayhan, K., Hagen, F., Wahyuningsih, R., Chakrabarti, A., Chowdhary, A., et al. (2012). Resistance of Asian Cryptococcus neoformans serotype A is confined to few microsatellite genotypes. PLOS ONE 7:e32868. doi: 10.1371/journal.pone.0032868

Park, B. J., Wannemuehler, K. A., Marston, B. J., Govender, N., Pappas, P. G., and Chiller, T. M. (2009). Estimation of the current global burden of cryptococcal meningitis among persons living with HIV/AIDS. AIDS 23, 525-530. doi: 10.1097/QAD.0b013e328322ffac

Paul, S., and Moye-Rowley, W. S. (2014). Multidrug resistance in fungi: regulation of transporter-encoding gene expression. Front. Physiol. 5:143. doi: $10.3389 /$ fphys.2014.00143

Pfaller, M. A. (2012). Antifungal drug resistance: mechanisms, epidemiology, and consequences for treatment. Am. J. Med. 125(Suppl.), S3-S13. doi: 10.1016/j.amjmed.2011.11.001

Pfaller, M. A., and Diekema, D. J. (2007). Epidemiology of invasive candidiasis: a persistent public health problem. Clin. Microbiol. Rev. 20, 133-163. doi: 10.1128/CMR.00029-06

Pierce, C. G., Chaturvedi, A. K., Lazzell, A. L., Powell, A. T., Saville, S. P., McHardy, S. F., et al. (2015). A novel small molecule inhibitor of Candida albicans biofilm formation, filamentation and virulence with low potential for the development of resistance. NPJ Biofilms Microbiomes 1:15012. doi: 10.1038/npjbiofilms.2015.12

Pierce, C. G., Saville, S. P., and Lopez-Ribot, J. L. (2014). High-content phenotypic screenings to identify inhibitors of Candida albicans biofilm formation and filamentation. Pathog. Dis. 70, 423-431. doi: 10.1111/2049632X.12161

Pierce, C. G., Uppuluri, P., Tristan, A. R., Wormley, FL Jr, Mowat, E., Ramage, G., et al. (2008). A simple and reproducible 96-well plate-based method for the formation of fungal biofilms and its application to antifungal susceptibility testing. Nat. Protoc. 3, 1494-1500. doi: 10.1038/nport.2008.141

Qi, X., Zhou, C., Li, P., Xu, W., Cao, Y., Ling, H., et al. (2010). Novel short antibacterial and antifungal peptides with low cytotoxicity: efficacy and action mechanisms. Biochem. Biophys. Res. Commun. 398, 594-600. doi: 10.1016/j.bbrc.2010.06.131

Ramage, G., Vande Walle, K., Wickes, B. L., and Lopez-Ribot, J. L. (2001). Standardized method for in vitro antifungal susceptibility testing of Candida albicans biofilms. Antimicrob. Agents Chemother. 45, 2475-2479. doi: 10.1128/AAC.45.9.2475-2479.2001

Ramage, G., VandeWalle, K., Lopez-Ribot, J. L., and Wickes, B. L. (2002). The filamentation pathway controlled by the Efgl regulator protein is required for normal biofilm formation and development in Candida albicans. FEMS Microbiol. Lett. 214, 95-100. doi: 10.1111/j.1574-6968.2002. tb11330.x

Rodrigues, C. F., Silva, S., and Henriques, M. (2014). Candida glabrata: a review of its features and resistance. Eur. J. Clin. Microbiol. Infect. Dis. 33, 673-688. doi: 10.1007/s10096-013-2009-3

Romani, L. (2011). Immunity to fungal infections. Nat. Rev. Immunol. 11, 275-288. doi: $10.1038 /$ nri2939

Sable, C. A., Strohmaier, K. M., and Chodakewitz, J. A. (2008). Advances in antifungal therapy. Annu. Rev. Med. 59, 361-379. doi: 10.1146/annurev.med.59.062906.071602

Schwartz, E. F., Diego-Garcia, E., Rodriguez de la Vega, R. C., and Possani, L. D. (2007). Transcriptome analysis of the venom gland of the Mexican scorpion Hadrurus gertschi (Arachnida: Scorpiones). BMC Genomics 8:119. doi: 10.1186/1471-2164-8-119

Silva, E. C., Camargos, T. S., Maranhao, A. Q., Silva-Pereira, I., Silva, L. P., Possani, L. D., et al. (2009). Cloning and characterization of cDNA sequences encoding for new venom peptides of the Brazilian scorpion Opisthacanthus cayaporum. Toxicon 54, 252-261. doi: 10.1016/j.toxicon. 2009.04.010

Sobel, J. D. (2006). The emergence of non-albicans Candida species as causes of invasive candidiasis and candidemia. Curr. Infect. Dis. Rep. 8, 427-433. doi: 10.1007/s11908-006-0016-6

Tati, S., Jang, W. S., Li, R., Kumar, R., Puri, S., and Edgerton, M. (2013). Histatin 5 resistance of Candida glabrata can be reversed by insertion of Candida albicans polyamine transporter-encoding genes DUR3 and DUR31. PLoS ONE 8:e61480. doi: 10.1371/journal.pone.0061480

Thaker, H. D., Sgolastra, F., Clements, D., Scott, R. W., and Tew, G. N. (2011). Synthetic mimics of antimicrobial peptides from triaryl scaffolds. J. Med. Chem. 54, 2241-2254. doi: 10.1021/jm101410t

Thompson, G. R. III, Wiederhold, N. P., Fothergill, A. W., Vallor, A. C., Wickes, B. L., and Patterson, T. F. (2009). Antifungal susceptibilities among different serotypes of Cryptococcus gattii and Cryptococcus neoformans. Antimicrob. Agents Chemother. 53, 309-311. doi: 10.1128/AAC.01216-08 
van der Weerden, N. L., Bleackley, M. R., and Anderson, M. A. (2013). Properties and mechanisms of action of naturally occurring antifungal peptides. Cell Mol. Life Sci. 70, 3545-3570. doi: 10.1007/s00018-013-1260-1

Wilkins, M. R., Gasteiger, E., Bairoch, A., Sanchez, J. C., Williams, K. L., Appel, R. D., et al. (1999). Protein identification and analysis tools in the ExPASy server. Methods Mol. Biol. 112, 531-552.

Zeng, X. C., Corzo, G., and Hahin, R. (2005). Scorpion venom peptides without disulfide bridges. IUBMB Life 57, 13-21. doi: 10.1080/15216540500058899

Zeng, X. C., Zhou, L., Shi, W., Luo, X., Zhang, L., Nie, Y., et al. (2013). Three new antimicrobial peptides from the scorpion Pandinus imperator. Peptides 45 , 28-34. doi: 10.1016/j.peptides.2013.03.026

Zhai, B., and Lin, X. (2013). Evaluation of the anticryptococcal activity of the antibiotic polymyxin B in vitro and in vivo. Int. J. Antimicrob. Agents 41, 250-254. doi: 10.1016/j.ijantimicag.2012.11.006

Zhao, Z., Hong, W., Zeng, Z., Wu, Y., Hu, K., Tian, X., et al. (2012). MucroporinM1 inhibits hepatitis B virus replication by activating the mitogen-activated protein kinase (MAPK) pathway and down-regulating HNF4alpha in vitro and in vivo. J. Biol. Chem. 287, 30181-30190. doi: 10.1074/jbc.M112.370312
Zhao, Z., Ma, Y., Dai, C., Zhao, R., Li, S., Wu, Y., et al. (2009). Imcroporin, a new cationic antimicrobial peptide from the venom of the scorpion Isometrus maculates. Antimicrob. Agents Chemother. 53, 3472-3477. doi: 10.1128/AAC.01436-08

Conflict of Interest Statement: The authors declare that the research was conducted in the absence of any commercial or financial relationships that could be construed as a potential conflict of interest.

Copyright (C) 2016 Guilhelmelli, Vilela, Smidt, de Oliveira, Álvares, Rigonatto, da Silva Costa, Tavares, Freitas, Nicola, Franco, Derengowski, Schwartz, Mortari, Bocca, Albuquerque and Silva-Pereira. This is an open-access article distributed under the terms of the Creative Commons Attribution License (CC BY). The use, distribution or reproduction in other forums is permitted, provided the original author(s) or licensor are credited and that the original publication in this journal is cited, in accordance with accepted academic practice. No use, distribution or reproduction is permitted which does not comply with these terms. 